\title{
Contradiction of Human Selection Activities to the Evolutionary Development of Ground Plants Will Lead to the Ecological Disaster
}

\author{
Chikov Vladimir Ivanovich* \\ Doctor of Biological Sciences, Kazan Institute of Biochemistry and Biophysics, FRC Kazan Scientific Center of RAS, Russia
}

*Corresponding author: Chikov Vladimir Ivanovich,Doctor of Biological Sciences, Kazan Institute of Biochemistry and Biophysics, FRC Kazan Scientific Center of RAS, Russia

\begin{abstract}
A contradiction has been established between human breeding activity and the evolutionary development of terrestrial plants, which lead to ecological disaster in the ocean. Experimental data are presented, and the conclusion is drawn that the elimination of these contradictions can not only maintain high productivity, restore soil fertility, but also get rid of a brewing ecological catastrophe in the oceans.
\end{abstract}

Keywords: Mineral fertilizers, root growth, drought tolerance, plant evolution; ecological disaster in the ocean.

\section{Introduction}

A billion years ago, plants that emerged from the ocean to live on land faced with an unknown factor - a drought. This required a revolutionary change in the structure of land plants. Waterconducting root growth intensification was probably one of the main tasks for plants throughout their history on land. But with the human development and selection of high-yield plants, this process was significantly influenced. Cultivated plant breeding by man, first of all, was aimed at gain in weight of the economically important organ (ear, +fruit, root tuber). The evolutionary useful organs such as roots have been ignored by the breeders and developed spontaneously. As a result, the root system of all cultivated plants was formed with a reduced weight as compared to the wild foregoing crops.

A great number of new and high-yield plant varieties were selected in the breeding process in the 20th century. However, as a result, the cultivated plants lost the root system size and became sensitive to adverse environmental factors (primarily to drought). The agronomists explained these phenomena by the fact that very favorable conditions were created for the plants to form a high yield and there was no need for them to develop a strong root system.
But it is obvious that the drought tolerance is determined primarily by the water-conducting roots' ability to keep pace with the water going deep into the soil rather than by the water molecule state in the cells.

The literature data accumulated to date allow us to conclude that the key activator for the growth of roots and other neoplasms in plants is nitric oxide NO [1].which can be formed in the apoplast of root cells from nitrate, including non-enzymatic way [2]. However, the more fertilizers were applied, the greater part of them was washed out by groundwater into the rivers and seas. According to the data of (the World Ocean Atlas 2013), by 1995, there were 305 dead zones with low oxygen level in the ocean across the globe. In 2007, there were 405 of them, and over the past decade, their number has increased tenfold. Such conclusions are contained in the results of studies of the international group of scientists. River mouths, coastal waters, and even remote from the shore areas become dead. The marine life could not be supported in dead zones. This is the fault of nitrogen-phosphate fertilizers entering the water from the river flows. This results in rapid single-celled algae bloom - the food for oxygen consuming bacteria. In combination with 
global warming, the process is only accelerating, as the high temperature is optimal for the algae (Figure 1).

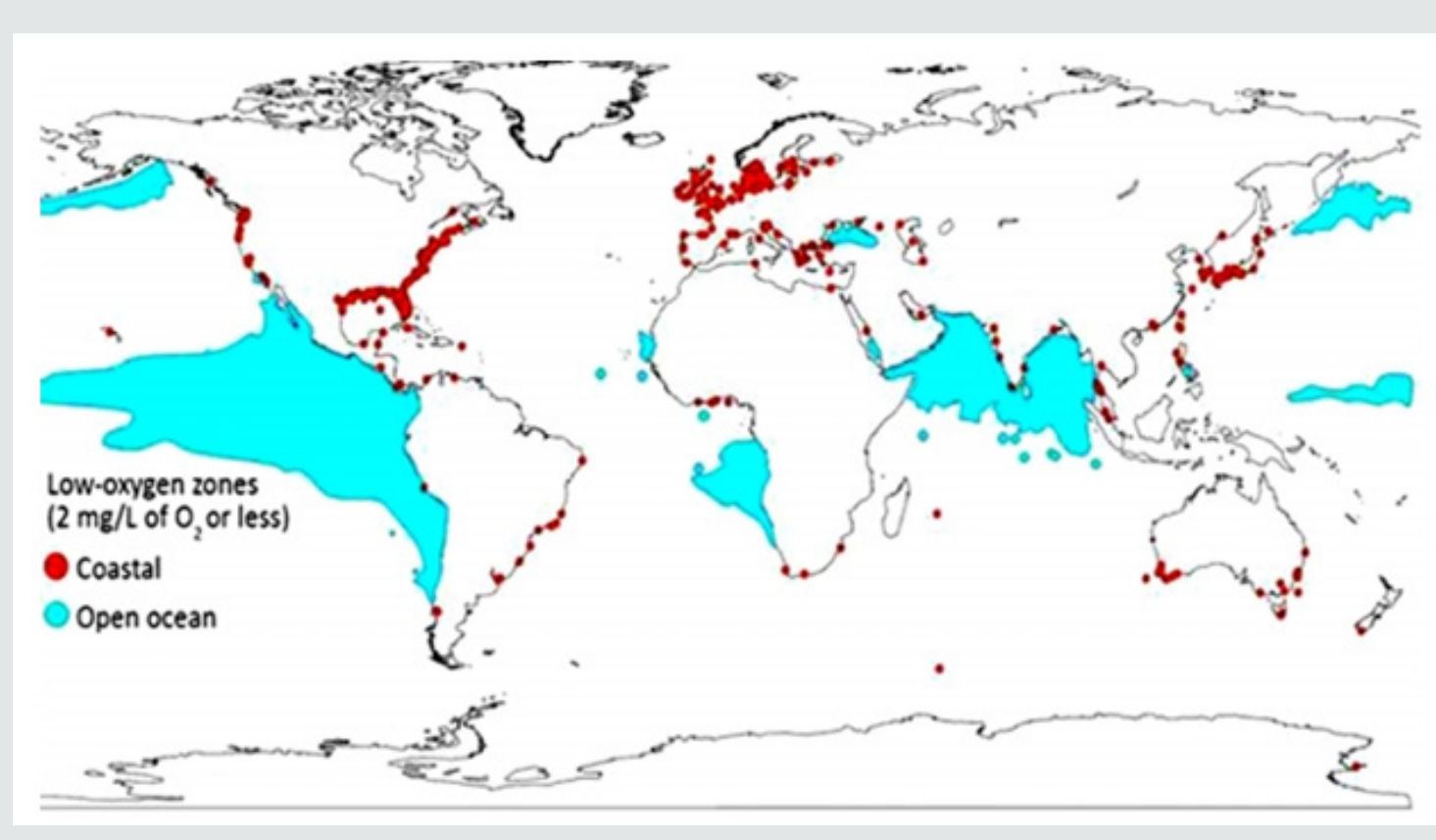

Figure 1.

World map with dead zones in the ocean. Low oxygen zones are spreading around the world. Red dots indicate locations on the coast where oxygen has fallen to 2 milligrams per liter or less, and blue areas indicate areas with the same low oxygen content in the open ocean.

(RJ Diaz/phys.org) Low-oxygen zones are spreading around the globe. Red dots indicate places on the coast where oxygen has plummeted to 2 milligrams per liter or less, and blue areas indicate zones with the same low-oxygen levels in the open ocean. Intensive selection of cultivated plants, particularly after the discovery of Chilean saltpeter, really enabled creation of conditions to provide high-yield plants with a low mass of roots. In fact, this has saved millions of human lives. But the breeders' work in this direction resulted in an increase in energy-intensive production of mineral fertilizers and their application to the soil. In Western Europe, this figure reached $1.5-2.0$ tons of fertilizers per hectare annually.

Our researches of different drought-tolerance varieties of barley carried out in Kazan Biochemistry and Biophysics Institute (in cooperation with the Tatar Agricultural Research Institute) showed that, early in ontogenesis, the root system of droughttolerant plants is two times larger [3]. Experimental variation of photosynthetic product mass (partial removal of leaves) or inhibition of their export from the leaves (increased nitrate level) showed that this process can be controlled. Our researches of different drought-tolerance varieties of barley carried out in Kazan Biochemistry and Biophysics Institute (in cooperation with the Tatar Agricultural Research Institute) showed that, early in ontogenesis, the root system of drought-tolerant plants is two times larger [3]. Experimental variation of photosynthetic product mass (partial removal of leaves) or inhibition of their export from the leaves (increased nitrate level) showed that this process can be controlled.

As can be seen from the above, breeding activity of human is in contradiction with the evolutionary development of land plants. In this regard, the purpose of our research was to check how root formation depends on the nitrates contained in the soil near the roots. It was assumed that if there are few nitrates in the soil, the roots will grow more intensively. Tests with different mineral nutrition levels (growing plants in soil or sand) have shown [4] that the root growth can be increased by 2-3 times (Figure 2). To this effect, it is necessary to reduce the nitrate level in the area of germinating seed (washed sand). An additional effect can be obtained [5] when plants are sprayed with zinc and copper ammoniates, which enhance the carbohydrate orientation of photosynthesis [6] and their export from leaves to economically important organs [7]. Since our previous works on the study of the photosynthetic carbon metabolism orientation showed its dependence on the photosynthetic product use intensity by acceptors [8], which also depends on the nitrate nutrition level [9], in conditions of low nitrate nutrition, when it is difficult to use carbohydrate photosynthetic products, sugars can be used for the synthesis of cellulose of cell walls only. In this stage of plant development, the latter is possible in the synthesis of root cell walls only. 


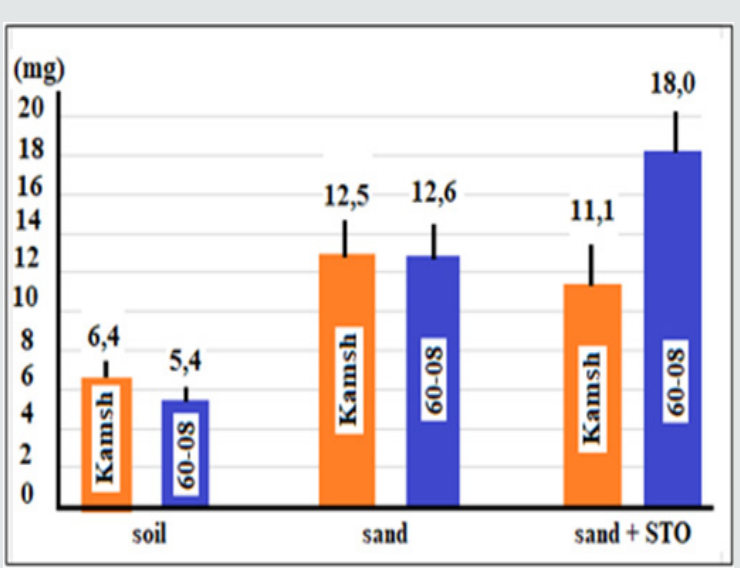

Figure 2: The mass of roots before tillering in resistant (Kamashevsky) and unstable (60-08) varieties of barley. On the abscissa axis is the soil in which the plants were grown (soil,sand and sand, but the plants were sprayed with a solution of (10-4 M) ammoniate STO.

The question now arises, what structures can be synthesized in sufficiently large amounts from pure carbohydrate substrates? It is obvious that these are carbohydrate polymers. This can not be a starch, since its accumulation is limited by the capacity of the respective compartments, and beside that, it does not solve the nitrogen deficiency problem of plants. Therefore, the end product of photosynthesis at this time is most likely the cell wall cellulose. Where can the cellulose be used in a plant? The answer is also obvious - in the building of cells with limited functionality (Figure 3).

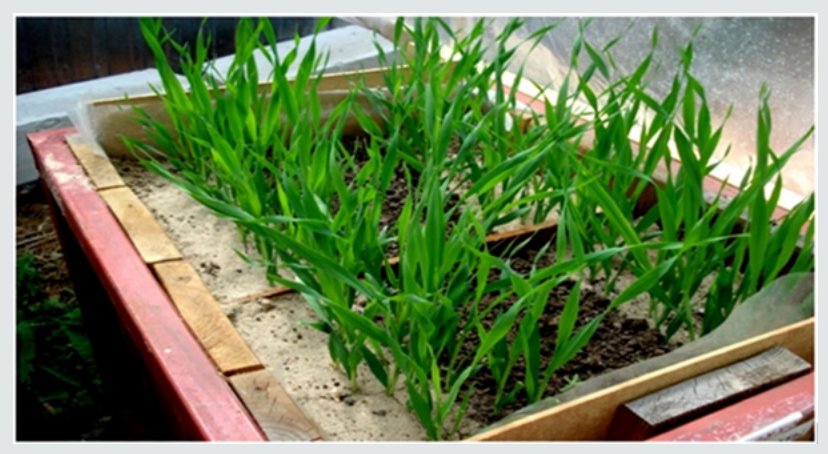

Figure 3.

\section{Photo}

At this stage of plant ontogenesis, these are highly vacuolated cells that grow by extension. These, of course, are cells of roots growing inland. Further developing this concept, one can expect a sharp relative increase in the proportion of cellulose in the dry mass of root tissues in plants growing in sand. Leaf cells cannot tolerate this without losing their functionality.

There is another aspect of the problem. In conditions of nitrogen deficiency and reduced amino acid synthesis, the carbon flux through the glycolytic route and photorespiration are reduced. This leads to attenuation of the stomata closure mechanism in case of inconsistency between light and dark reactions of chloroplasts, as we have shown it in [10]. The increased flow of CO2 into the leaf probably even more enhances the carbohydrate orientation of photosynthesis. Testing of this idea in the conditions of artificial drought showed (photo) that if seeds are sown in a small zone of sand (furrow of $5 \times 5 \mathrm{~cm}$ ), the root availability increases almost twice (Table 1).

Table 1: Growing conditions influence on dry root mass of different varieties of string barley, (g).

\begin{tabular}{|c|c|c|c|c|}
\hline Variant & Shoot & Roots & All plant & $\begin{array}{l}\text { Root/ } \\
\text { Shoot }\end{array}$ \\
\hline \multicolumn{5}{|l|}{$\begin{array}{l}\text { Optimal water } \\
\text { supply }\end{array}$} \\
\hline Control, soil & $3,22 \pm 0,22$ & $1.38 \pm 0,52$ & $\begin{array}{c}4,60 \pm 1 \\
77\end{array}$ & 0,43 \\
\hline \multicolumn{5}{|l|}{ Drought } \\
\hline Soil + soil & $1,15 \pm 0,15$ & $0,82 \pm 0,18$ & $\begin{array}{c}1,97 \pm \\
0,47\end{array}$ & 0,71 \\
\hline Soil + sand & $1,09 \pm 0,06$ & $1,41 \pm 0,10$ & $\begin{array}{c}2,50 \pm \\
0,25\end{array}$ & 1,29 \\
\hline
\end{tabular}

*The sand was added before sowing into the groove with a section of $5[5 \mathrm{~cm}$, where the seeds were sown.

Thus, the root growth, which means drought tolerance and increased symbiosis of the plant with soil microorganisms, increases with a decrease in the nitrate concentration near the seeds. This idea was tested in the field on barley sowing. For this purpose, the seed and fertilizer flows were separated during the sowing.

\section{Checking The Idea Forcing The Production Process Of Plants By Separating Seeds From Fertilizers At Seeding}

Field test method. The tests were carried out using industrial seeds of Nur-R3 barley variety. In the absence of the required sowing machine, conventional sowing machine SZS-3,6 was used, but it was transformed as follows (Figure 4). This sowing machine has 24 openers, each supplies seeds from one box, and mineral fertilizers from the other through corrugated plastic tubes. Both flows can be controlled and even (for fertilizers) completely blocked by latches. Therefore, we left one opener unchanged (where both seeds and fertilizers are supplied), in two next openers the fertilizer flow was completely blocked. As a result, eight openers of the sowing machine worked normally. In these openers, seeds were sown together with fertilizers, and the remaining sixteen ones (two after each regular one) sowed only seeds. As a result, the fertilizer amount per unit area decreased three-fold, while the total number of seeds sown remained unchanged. 


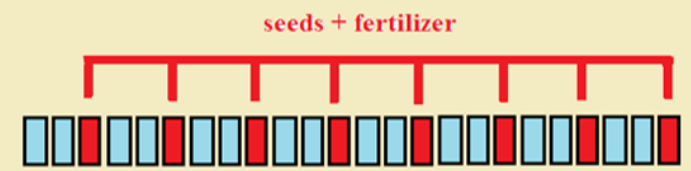

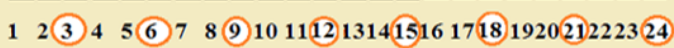

Coulter numbers of seeding machine C3-3,6

$\square$

- seeds without fertilizer

seeds with fertilizer

Figure 4: The scheme of regulation of coulters of the SZS3.6 drill for partial separation of seed flows during sowing.

Therefore, the initial stage of development of seeds sown in sixteen openers was in a fertilizer-free environment. But these plants could obtain the required quantity of mineral nutrition from the next row later, as necessary. Therefore, the fertilizer use efficiency should increase. Due to the cold weather during the test, the sowing was completed on May 9, 2018. The number of seedlings in different drill rows was tested on May 30, 2018. The number of plants per linear meter in the row was calculated. And so that, by moving a ruler across the drill rows to the right (each time one row further), the number of plants in seven-eight rows was calculated repeatedly. On June 5, 2018, plants were sprayed with ammoniate solution (concentration of $10-4 \mathrm{M}$ ) at a selected section of the levelled planting area ( $3 \times 7 \mathrm{~m})$. Then, at the end of tillering, on 16th of June, plant samples from different rows were collected (including sprayed with ammonia) for evaluation of tilling capacity and weight of the whole plant. The sampling procedure was the same as for the germinating capacity evaluation. The samples were collected from each next row by moving from the initial row to the right, step by step. The reference samples (not treated with ammonia) were sampled from the same rows as the samples of plants sprayed with ammoniates. The total number of plants in each test option was 12-
15 (for fertilized options) and 18-24 for the unfertilized ones. The tables show the average statistical data with a standard error.

\section{Results and Discussion}

The calculation of plant number per meter in the adjacent rows showed explicit dependence on fertilizers in the soil near the seeds (Figure 5). In fertilized areas, the seedling number was less (by $27 \%$ ). This fact confirms the well-known depressing effect of mineral fertilizers on the germinating ability. Therefore, it is possible to considerably save expensive seed material by dividing the seed and fertilizer flows when sowing. The further morphometric analysis of the test barley showed its reliable dependence both on fertilizers in soil and on plant treatment by ammoniates. These effects had an impact on sprout formation (Table 2). Fertilizers reduced tilling capacity both in the reference plants (without ammoniate treatment), and in the treated ones. It should be noted that the ammoniate effect on tilling capacity manifested itself to a greater extent in the absence of mineral fertilizers. This shows somewhat of an antagonism of fertilizer and ammoniate effect on the plant metabolism.

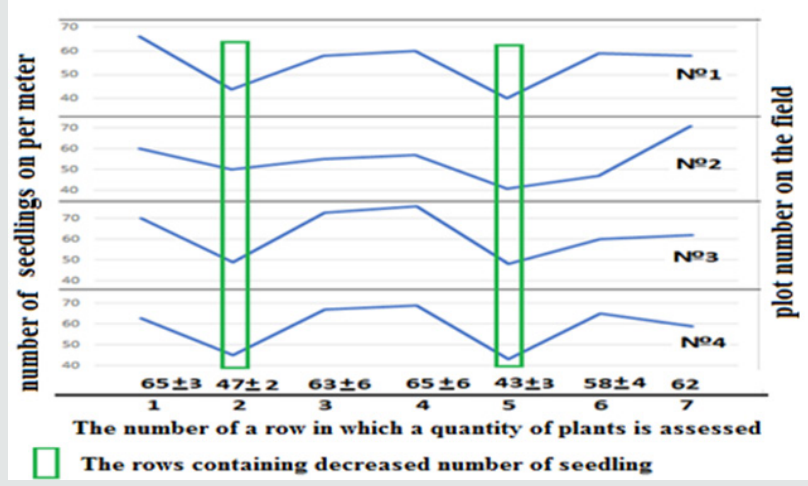

Figure 5: The number of seedlings per meter in different rows of sowing barley varieties Nur-R3.

Table 2: The effect of the presence in the row of mineral fertilizers and the treatment of sowing with ammoniates on the number of tillering shoots in the Nur-R3 barley plants at the end of the tillering phase.

\begin{tabular}{|c|c|c|c|}
\hline The presebce of mineral fertilizers in the soil & Control & Treatment with ammoniates & \% to control \\
\hline Without fertilizers & $1,95 \pm 0,12$ & $3,15 \pm 0,16$ & 161 \\
\hline With fertilizers & $1,66 \pm 0,08$ & $2,42 \pm 0,11$ & 145 \\
\hline Effect of fertilizers (\%) & -15 & -23 & \\
\hline
\end{tabular}

Our previous researches $[5,6]$ of the mineral fertilizer (particularly nitrates) and ammoniate effect on photosynthesis allow to assume that they effect mainly through the change of photosynthetic metabolism and transport of the main end product of photosynthesis - saccharose from the leaves. Evaluation of photosynthetic metabolism of 14C [8] showed its dependence on the intensity of assimilant export from the leaves and the activity of photosynthetic product use by acceptors, which decreased under the influence of nitrates [9]. In terms of lower nitrate nutrition, when the use of carbohydrate photosynthetic products in synthetic processes of new tissues is complicated, sugars can be used only for synthesis of cell wall cellulose. The latter is possible only for the synthesis of the root cell walls, as these cells are highly vacuolated and cellulose is the the basis of their dry weight. Table 2 . The effect 
of the presence in the row of mineral fertilizers and the treatment of sowing with ammonia on the number of tailoring shoots in the NurR3 barley plants at the end of the tillering phase.

Hence, it follows that the crops should be sown in the unfertilized soil to increase the root mass. The symbiosis of plants with soil microorganisms is of great importance. The abovementioned process created the well-known two-meter chernozemic soil. But mineral fertilizers suppress microorganism activity. Similar effects of these factors were found in the analysis of dry mass of plants (Table 3). However, in this case, the ammoniate effect with mineral fertilizers was less significant. This allows making a conclusion about the possibility of further intensification of the root formation process after determination of details of this mechanism. It should be noted that ammoniates work in very low concentrations (up to 10-5-6M), which suggests that metal ions affect not the $\mathrm{pH}$ of the entire aquatic medium in the intercellular space, but directly the protein molecule of invertase and changes its reactive center conformation (to be determined in further studies). But data available show that the cost of the agent is negligible and the efficiency is high. Moreover, the leaves treated with ammoniates retain increased sugar export function and photosynthesis intensity (more open stomata) until the end of their effect. Conclusion The experiments clearly indicate the need to abandon mineral fertilizers in agriculture.

Table 3: The effect of the presence in the row of mineral fertilizers and the treatment of sowing with ammoniates on the mass of plants of the Nur-R3 barley plants at the end of the tailoring phase.

\begin{tabular}{|c|c|c|c|}
\hline The presebce of mineral fertilizers in the soil & Control & Treatment with ammoniates & \% to control \\
\hline Without fertilizers & $1,17 \pm 0,08$ & $1,98 \pm 0,09$ & 169 \\
\hline With fertilizers & $1,08 \pm 0,05$ & $1,67 \pm 0,08$ & 155 \\
\hline Effect of fertilizers (\%) & -9 & -16 & \\
\hline
\end{tabular}

The plant root system in the area of low nitrate level will be more actively interacting with the soil microbial flora, which would supply the required amount of nitrogen due to microbiological absorption of air nitrogen. In addition, microbes will increase the availability of soil-bound phosphorus and potassium to plants. Finally, it is necessary to step-by-step adopt the agricultural practices that will allow to intensify development of cultivated plant root systems to a degree which will gradually exclude the use of mineral fertilizers. The increased root mass will be the basis for accumulation of soil organic mass which will increase its fertility over time. It requires the efforts of agricultural researchers and scientists to search the ways to maximize the root mass. It is worth to note that symbiotic microorganisms work in drought conditions as well. Furthermore, microorganisms protect the plant from water loss, as they isolate the wet root with their bodies. Less rain-wash of mineral fertilizers from soil will reduce their transfer to rivers, which would improve the ecological situation in nearshore zone (Figure 2).

Since the development and serial production of a new sowingmachine that will separate the seed and fertilizer flows in the sowing process will take time and requires optimization studies, in the next vegetation year, the extended testing followed by application of the above technology using the old sowing-machines can be carried out as the first step in validation through elaboration of this technology. This technology will most likely urge to change the plant distribution pattern in the sowing area (at optimal distance from the applied fertilizers). This will provide formation of a strong photosynthetic apparatus of the plant to ensure a high yield. All this will allow getting the following benefits as compared to the old agricultural technology: — saving (by three to four times) of mineral fertilizers applied into the soil, since away from the plant root system, more than half of them are washed out by rainwater and affects the environmental situation. - increase of drought tolerance in high-yield varieties of cultivated plants sensitive to even minor drought. - increase of cultivated soil natural fertility, since they contain increased amounts of postharvest organic matters. - implementation of this agricultural technology is an important way to reduce $\mathrm{CO}_{2}$ in the air. If the human efforts will be aimed at gain in the plant root mass, it will not only increase the soil fertility, but also will gradually bind the great amount of the atmospheric carbon dioxide in the organic matter of the soil. And all this is feasible, because the formation of thick ( $2 \mathrm{~m}$ ) chernozems in nature occurred without mineral fertilizers. It is only necessary to fully develop the root system not only in agricultural plants, but also in meadow and forest ones. It should be noted that the reduction in the use of mineral fertilizers in agriculture is also an important factor in energy saving, since their production consumes about half of all energy resources of mankind. And this is the main way to save from, yet unconscious, probability of ecological catastrophe and, as a consequence, the disappearance of humanity on Earth.

If the efforts of mankind will be aimed at increasing the mass of roots in plants, this will not only increase soil fertility, but will gradually bind a huge amount of atmospheric carbon dioxide in the organic matter of the soil. And all this is doable, because in nature, the formation of thick ( $2 \mathrm{~m}$ ) chernozems occurred without mineral fertilizers [11]. There is reason to believe that the fires that have become more frequent in recent years in the forests of Siberia and America are also associated with a reduction in the mass of tree roots as a result of the transfer of mineral fertilizers by winds along 
with dust from agricultural areas. For example, fertilizers can be brought into Russian Siberia with Avganz (dust clouds covering the summer sun) from Central Asia, where mineral fertilizers are used intensively. The negative role of forest fire is also played by incinerators, which emit nitrogen oxides into the atmosphere. Getting directly into the leaves, they activate the synthesis of calose, which clogs the pores in the walls of the phloem vessels, preventing the transport of sugars to the roots. In such trees (with a small root size), even from a small drought, there is a possibility of a fire.

\section{References}

1. Sun $\mathrm{CH}$, et al. (2017) Nitrate: a crucial signal during lateral roots development. Front. Plant Sci 8: 485.

2. Neill S, Desikant R, Hancock JT (2003) Nitric oxide signalling in plants. New Phytologist 159: 11-35.

3. Blokhin VI, Tagirov MSH, Chikov VI (2016) Influence of mineral nutrition on tillering process of different morphological biotypes of spring barley Niva Tatarstana (2-3): 40-42.

4. Chikov VI, GA Akhtyamovaa, SN Batasheva, Diurbin DS, Tagirov MSH, Blokhin VI (2017) Root formation in the pre-heading period in different morphobiotypes of barley Niva Tatarstana (3-4): 50-52.
5. Chikov VI, GA Akhtyamova (2018) Breeding genetics and evolution of plants: metabolic link enetics and bioengineering 22 (4): 13-19.

6. Chikov VI, GG Bakirova, SN Batasheva, AA Sergeeva (2006) The influence of ammoniates on $14 \mathrm{CO}_{2}$ assymilation in flax // Biologia Plantarum 50(4): 749-751.

7. Chikov VI, Abdrakhimov FA, Bakirova GG, Batasheva SN (2009) The role of sink-source relationships between different organs in regulation of photosynthesis and productivity. Acta Horticulture 835: 87-98.

8. Chikov VI (1987) Photosynthesis and transport of assimilates. Moscow: Science. 188p.

9. Batasheva SN, Abdrakhimov, Bakirova GG, Chikov VI (2007) Effect of nitrates supplied with the transpiration flow on assimilate translocation. Russian Journal of Plant Physiology 50: 373-380.

10. Chikov VI, Akhtyamova GA, Batasheva SN, Mikhailov FL, Khamidullina (2015) Effect of silencing of the apo plastic invertase gene on photosynthesis in tomato. Russ J Plant Physiol 62: 39-44.

11. Kovda VA, Pachepsky PA (1989) Soil resources of the USSR, their use and restoration. Pushchino.

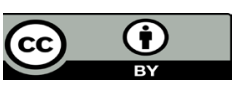

This work is licensed under Creative Commons Attribution 4.0 License

To Submit Your Article Click Here: Submit Article

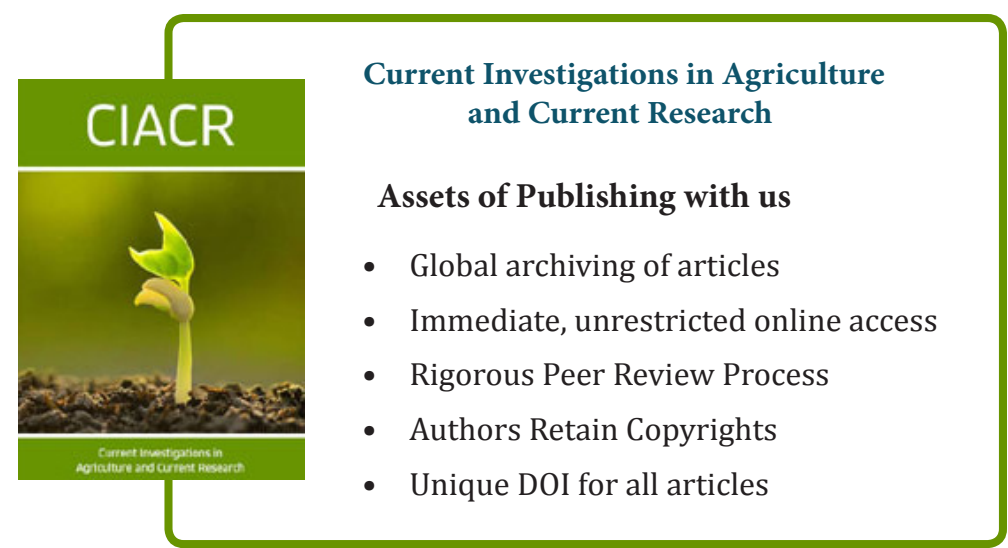

